\section{Sanctioning of breakdown infringements during the knockout stage of the 2019 rugby world cup}

\author{
Scott Mitchell and Gregory J Tierney $\mathbb{D}$
}

\& Coaching

$0(0)$ I-8

(C) The Author(s) 2020

(c) (i)

Article reuse guidelines: sagepub.com/journals-permissions DOI: $10.1177 / 1747954 / 20970922$ journals.sagepub.com/home/spo (S)AGE

\begin{abstract}
The breakdown is a complex and dynamic facet of rugby union, often containing multiple players from each team. It is the responsibility of coaches and trainers to ensure players are prepared to comply with the World Rugby laws of the game to encourage safe and fair play between all participants. The aim of this study was to investigate player adherence and sanctioning of infringements at the breakdown during the knockout stages of the 2019 Rugby World Cup. Breakdown infringements according to World Rugby laws were identified using match video recordings of the 8 matches. Each breakdown was individually analysed by coding any infringement that had occurred and the sanctioning outcome of the breakdown. A total of 898 breakdowns were coded, of which $37.7 \%(n=339)$ were deemed to involve illegal play. $79.9 \%$ of breakdowns involving illegal play were not penalised with the majority of infringements being "head and shoulders below hips" $(33.5 \%, \mathrm{n}=\mathrm{I63})$, "off feet" $(13 \%, \mathrm{n}=63)$ and "offside" $(10.5 \%, \mathrm{n}=5 \mathrm{I})$. The attacking team were responsible for $70.0 \%(n=340)$ of all breakdown infringements despite being penalised less than the defending team. A high number of infringements occurred at the breakdown and went unsanctioned in the knockout stages of the 2019 Rugby World Cup. Future work focused on technology, training or rule amendments may be required to improve player adherence and sanctioning of infringements at the breakdown, such that they protect players and are in keeping with the dynamics of the modern game.
\end{abstract}

\title{
Keywords
}

Injury prevention, performance analysis, rugby union

\section{Introduction}

Rugby union is a team sport characterised by short bouts of high intensity activity combined with repeated high-impact collisions between 30 players. ${ }^{1}$ Due to the physical nature of the game, the risk of injury is high. It is suggested that most injuries result from contact phases of play, with the tackle and the ruck being the first and second most likely causes of injury, respectively. ${ }^{2}$ Fuller et al. ${ }^{3}$ reported that ruck cleanouts were responsible for up to $17 \%$ of injuries in youth and senior rugby, with players in forwards positions being most vulnerable to neck and spinal injuries in these situations.

Players are required to follow the laws of the game assigned by World Rugby, the global governing body for rugby union, put in place to allow players to play within the spirit of the game and more importantly, to protect the welfare of players. ${ }^{4}$ As rugby union is a relatively 'new' sport, turning professional in 1995, the game is constantly evolving to make the sport safer for participants. This encourages World Rugby to review the laws regularly and make rule amendments where they see fit. This means that players and coaches must adapt their tactics and styles of play to take advantage of any freedom or restriction brought about by these changes. ${ }^{5}$ It is the responsibility of the on-field referee to interpret and apply the laws of the game, and in doing so, protect players from potential injury risk. ${ }^{5}$

Reviewers: Ben Jones (Leeds Beckett University, UK) Steve den Hollander (University of Cape Town, South Africa)

School of Biomedical Sciences, University of Leeds, Leeds, UK

\section{Corresponding author:}

Gregory J Tierney, 4.02 Miall Building, School of Biomedical Sciences, University of Leeds, Leeds LS2 9NL, UK.

Email: g.tierney@leeds.ac.uk 
The sport's evolution since the inaugural Rugby World Cup (RWC) in 1987 is demonstrated by McCormick. ${ }^{6}$ One of the most significant changes identified is that the 'ball in play time' has increased over the years. The 1995 RWC saw an average of just 25 minutes 45 seconds 'ball in play time', compared to 34 minutes and 21 seconds in 2019 RWC - an increase of roughly a third in the latter competition. The knockon effect of this is an increased number of breakdown events. In 1987, teams averaged 25 rucks per game, compared to 82 in $2019,{ }^{6}$ making the ruck one of the most frequently occurring events within a match. This emphasises the greater fitness levels required of the modern-day player, allowing for higher intensity games with longer periods of continuous play.

The breakdown is a rugby term for the short period of play just after the tackle and before and during the ruck. ${ }^{7}$ A ruck is formed when one or more players from opposing teams are in contact, on their feet, and competing over the ball which is on the ground, in order to retain (attacking team) or regain (defending team) possession. ${ }^{5}$ A recent study analysed 7,393 physical interaction events in the Championship and Six Nations competitions to determine that $65 \%$ of collisions resulted in a ruck in professional rugby. ${ }^{8}$ The findings of Ortega et al. ${ }^{9}$ and Kraak and Welman ${ }^{10}$ show that a team's ability to turn the ball over at the ruck may be a key performance indicator associated with team success. For this reason, the refereeing of the breakdown may have a significant influence on the outcome of a match, highlighting the need for this to be carried out accurately and uniformly across all competitions to ensure a fair game throughout the sport.

Mascarenhas et al. ${ }^{11}$ implemented a video-based training program combined with informed knowledge from experts to guide decisions made by referees in real-game breakdown scenarios. The researchers reported $17 \%$ improvement in the accuracy of decision making by referees following the program, concluding that shared mental model training is an appropriate means for improving refereeing performance, and stressing that this may have significant implications in the wider scope of consistent and accurate refereeing. Further, Spitz et al. ${ }^{12}$ used a visual search paradigm to illustrate that elite referees spent a significantly larger amount of time fixating on the most informative area of the attacking player - the contact zone (i.e. the body part which was involved in the possible infringement) and less time fixating on the non-contact zone (i.e. the body part which was not involved in the possible infringement) than a non-elite referee. These studies both show improvements in referee performance as a result of different training methods and suggest that if World Rugby were to introduce similar programs for their referees, this may lead to greater consistency to how the breakdown is officiated. In order for the breakdown to be a safe aspect of the game, players must use specific techniques aligned with World Rugby's Laws of the game presented in Appendix 1.

Kraak et al. ${ }^{13}$ analysed over 22,000 rucks from 120 matches over the course of the 2018 Super Rugby Competition, examining the rate of sanctioning of illegal and dangerous ruck cleanouts throughout the competition, in which eight separate types of illegal ruck cleanout were identified and coded. Findings showed that $9 \%(n=2111)$ of all ruck cleanouts were illegal, $93 \%(n=1963)$ of which, were not sanctioned by the referee. As well as this, more than half of the illegal ruck cleanouts not sanctioned by the match officials were deemed dangerous. Similar findings reveal that during the South African Under-18 Craven Week rugby tournament, $59 \%$ of illegal tackles were not penalised appropriately by the referees. ${ }^{14}$ Failure to penalise such incidents in a youth setting increases the risk of players continuing to carry out the same techniques into senior rugby where collisions are much greater, and risk of injury is increased..$^{15}$ Within professional English rugby, over 6000 tackle events were analysed across the 2003/04 and 2005/06 Premiership seasons to reveal that only $6 \%$ (14 out of 238) of the high tackles (in accordance to the laws of the game), were penalised by the on-field referees. ${ }^{3}$ These studies show that there is a clear problem with the accuracy to which referees are interpreting and implementing the laws of the game within current rugby competition. Therefore, the aim of this study was to investigate player adherence and sanctioning of breakdown infringements during the knockout stages of the 2019 RWC.

\section{Methods}

Televised video recordings $(n=8)$ of the knockout games from the 2019 RWC were used. Kinovea video software was used to analyse the match footage, allowing frame-by-frame viewing by a rugby video analyst. A coding database was created to store all breakdown information from each match. This included: number of breakdowns, game time of breakdowns, breakdown infringements and breakdown outcome (turnovers and penalties). Each breakdown was analysed individually, assessing any infringements made by both the attacking and defending teams. A binary coding system was used to identify which infringements had been made during the breakdowns with ' 0 ' indicating no infringement and ' 1 ' indicating an infringement for a particular offense. Given that the video data was in the public domain, ethical approval was not required, similar to previous rugby union video analysis studies. ${ }^{16-18}$ 
A ruck was defined as a phase of play where at least one player from each team are in contact, on their feet and over the ball which is on the ground. ${ }^{5}$ Ruck frequency was cross-referenced through statistics providers Match Stats. ${ }^{19}$ Whilst the number of total rucks identified were consistent between Match Stats and this research, only rucks where a player from both teams were actively engaged in the breakdown by competing for the ball were analysed, therefore breakdowns where players from the defending team were not actively engaged by attempting to regain possession, have been excluded from analysis. Analysis of "Head and shoulders below hips" (HSBH), infringement (A) in Appendix 1, was only conducted on nonjackaler players. Due to audio being unavailable, infringement (H) in Appendix 1, "use within 5 seconds" was not included in analysis as the referee's call was inaudible.

The percentage occurrence of each infringement was reported with $95 \%$ confidence interval. ${ }^{20}$ To assess inter-rater reliability, an external reviewer (sport scientist and Tier-3 international rugby player) conducted analysis on the same 25 cases as the main reviewer.

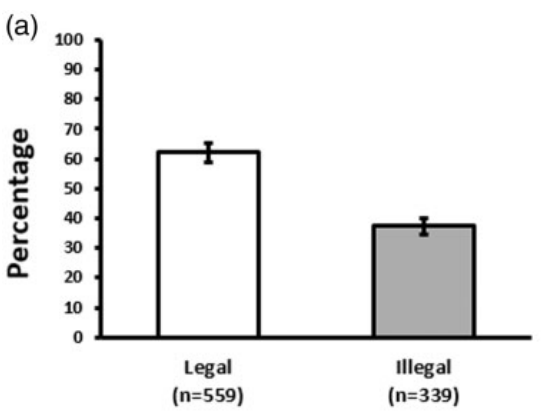

(c)

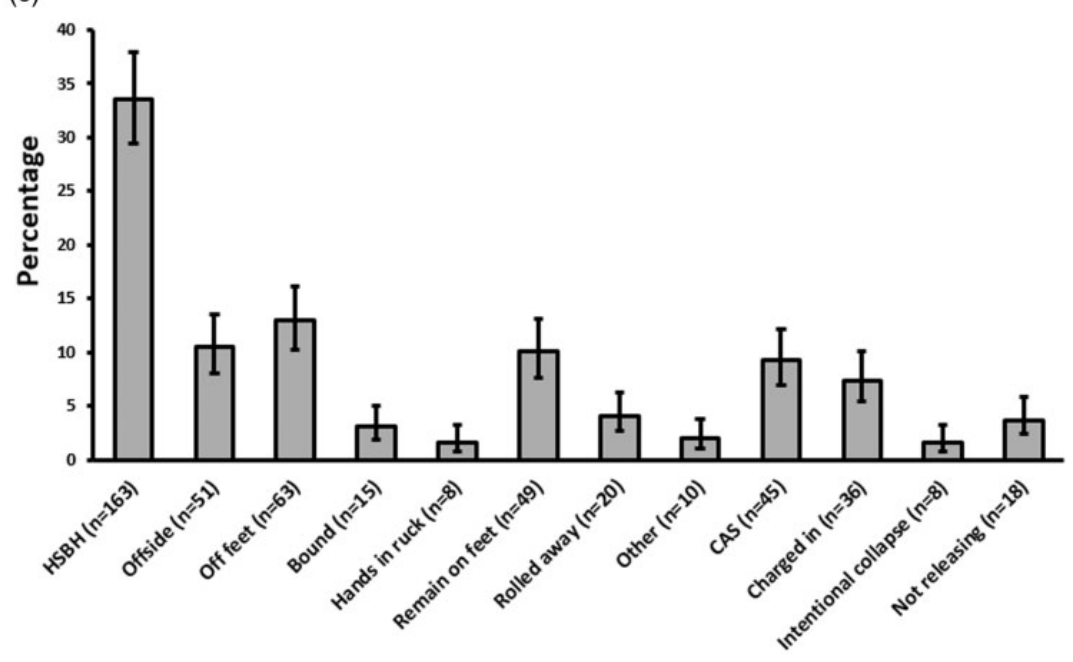

Reliability was tested using Cohen's kappa $(\kappa)$ in SPSS. Similarly, intra-rater reliability was assessed using Cohen's $\kappa$ following the main reviewer's reanalysis of the original 25 cases one month after the initial review. Cohen's $\kappa$ values of 0.823 and 0.841 were calculated for inter-rater and intra-rater reliability, respectively. A Cohen's $\kappa$ value greater than 0.8 indicates a near perfect agreement. ${ }^{21}$

\section{Results}

Of the 898 breakdowns analysed, 37.9\% $(n=339)$ involved illegal play (Figure 1(a)). The referees did not sanction $79.9 \%(\mathrm{n}=271)$ of breakdowns involving illegal play (Figure 1(b)). A total of 486 infringements were identified, equalling 1.43 infringements per illegal breakdown (0.54 infringements per total breakdowns). "Head and shoulders below hips" contributes 33.5\% $(\mathrm{n}=163)$ of total infringements (Figure 1(c)). "Off feet" $(13 \%, \mathrm{n}=63)$ and "offside" $(10.5 \%, \mathrm{n}=51)$ are the next highest contributing infringements.

Figure 2 shows that match officials failed to sanction "Head and shoulders below hips", "bound" and "remains

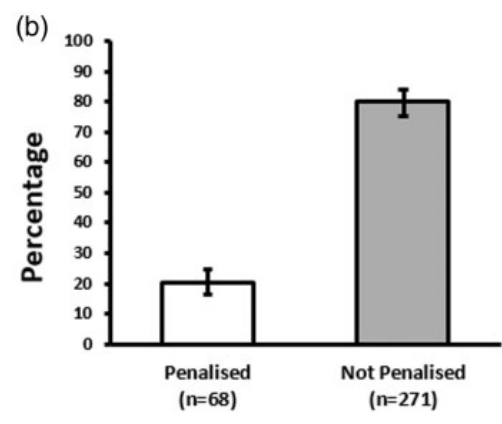

Figure I. (a) Total legal and illegal breakdown events. (b) The proportions of illegal breakdowns penalised. (c) The offences committed within the illegal breakdowns. $\mathrm{HSBH}=\mathrm{Head}$ and shoulders below hips; CAS = Contact above shoulder. 
(a)

HSBH

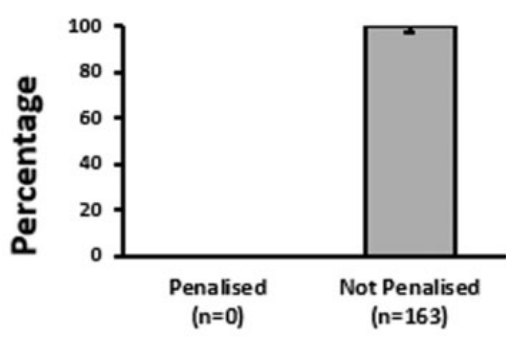

(c)

Off feet

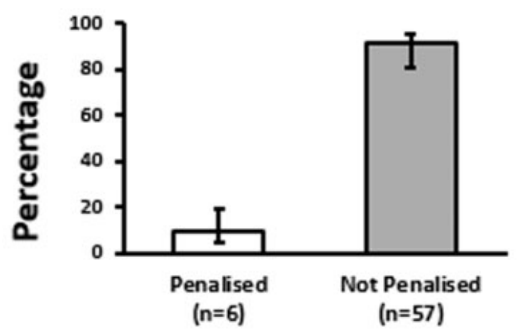

(e) Hands in ruck

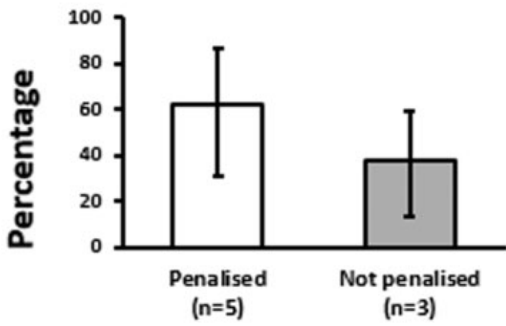

(g)

Rolled away

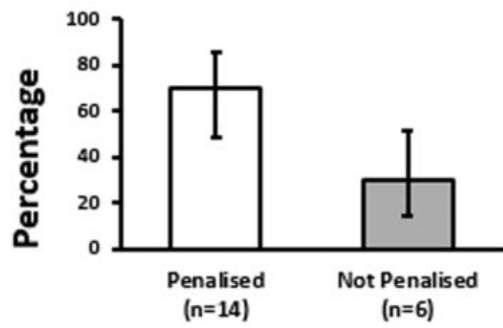

(b)

Offside

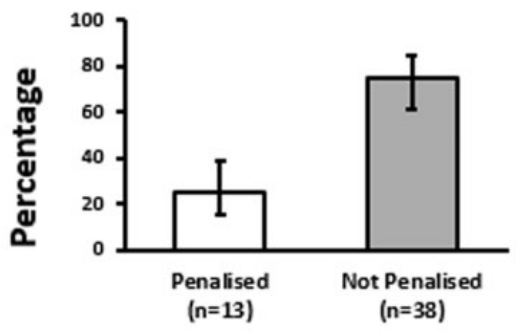

(d)

Bound

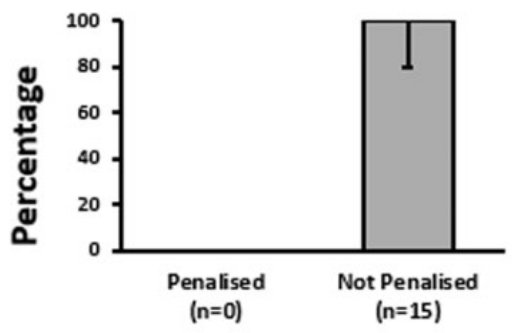

(f) Remains on feet

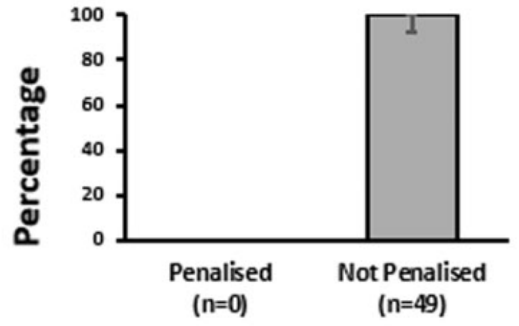

(h)

Not releasing

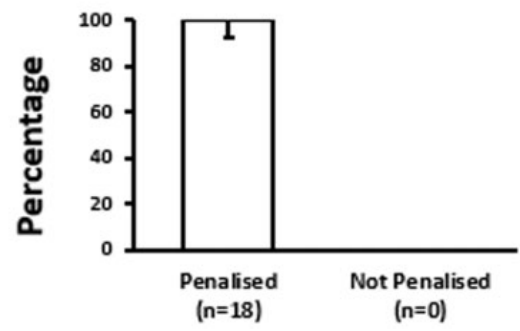

Figure 2. The proportion of penalised versus non-penalised breakdowns for each individual infringement. Ten breakdown infringements were categorised as 'Other' of which 3 were penalised (e.g. any attempt to kick the ball out of the ruck).

on feet". "Not releasing" was the only infringement to be sanctioned $100 \%$ correctly. Figure 3 displays the infringements World Rugby refer to as "dangerous play" within a ruck. Only $5.6 \%$ of dangerous play offences were penalised. The attacking team contributed $70.0 \%(n=340)$ of total infringements (Figure 4(a)). Despite having more infringements, the attacking team was penalised less $(43.8 \%, \mathrm{n}=28)$ than the defending team $(56.2 \%, \mathrm{n}=36$ ) (Figure 4(b)). Figure 4(c) shows that $6.8 \%$ of all breakdowns led to a turnover, of which $80.3 \%(n=49)$ involved illegal play (Figure $4(d))$.

\section{Discussion}

This study investigated player adherence and sanctioning of breakdown infringements during the knockout stages of the 2019 RWC. Our main findings indicate that $37.9 \%$ of all breakdown events contained at least one illegal infringement, of which $79.9 \%$ were not sanctioned by officials. Another main finding was that only $5.6 \%$ of all dangerous play infringements were penalised appropriately in accordance with World Rugby regulations. ${ }^{5}$ Finally, the defending team were 


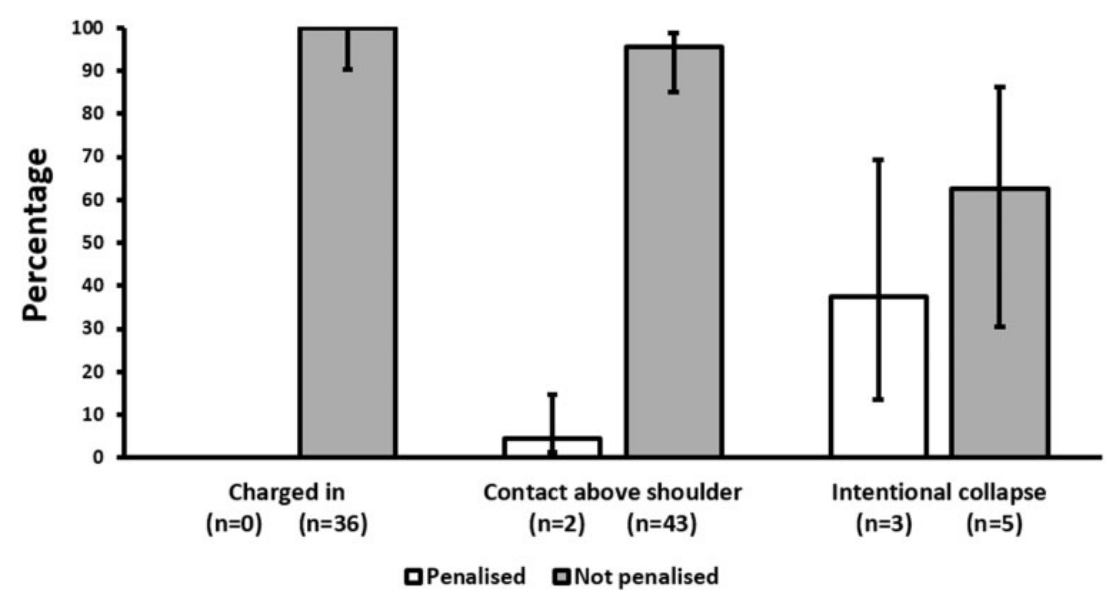

Figure 3. The proportion of penalised versus non-penalised breakdowns for each infringement classified as "dangerous play".
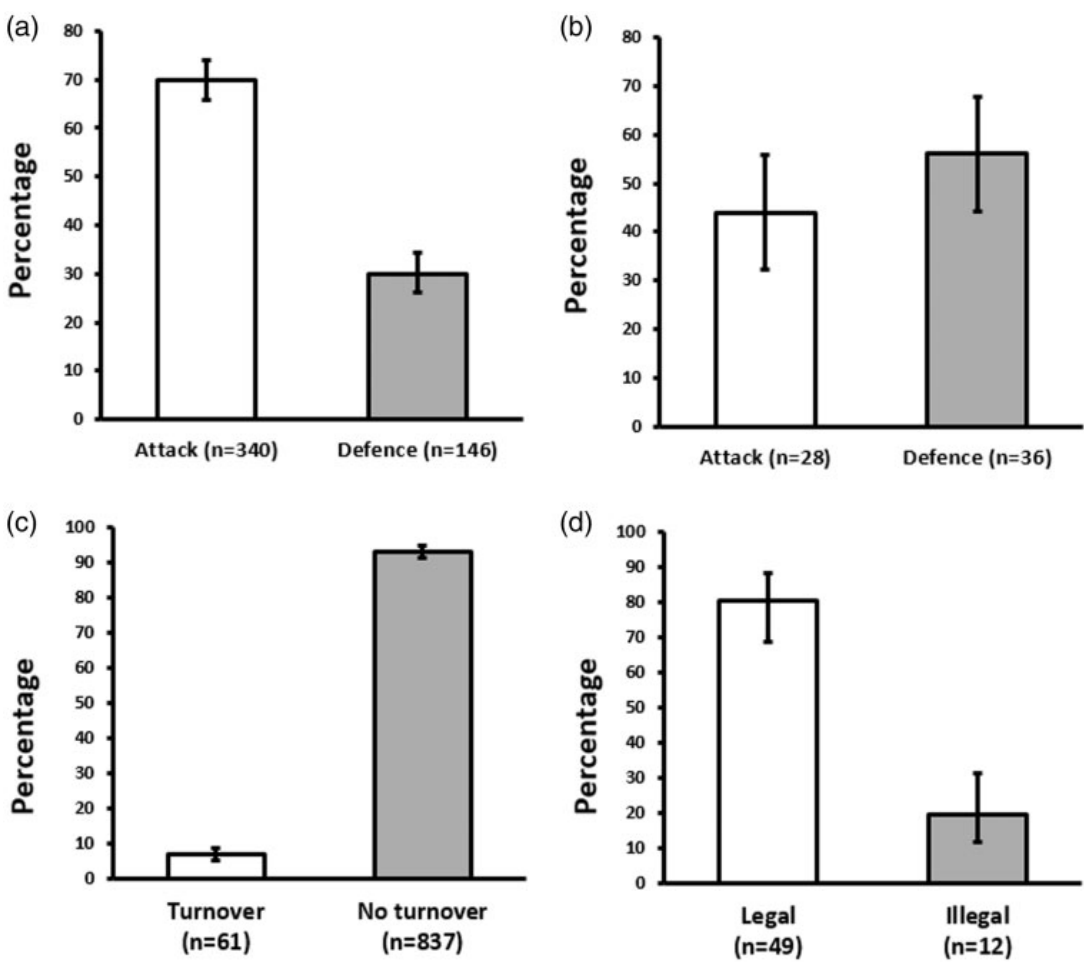

Figure 4. (a) Infringements made by the attacking and defending teams. (b) Penalties conceded by the attacking and defending teams (c) Breakdowns leading to a turnover in possession. (d) Legality of breakdown turnovers.

penalised more than the attacking team, despite making fewer total infringements.

The breakdown is a complex and dynamic facet of the game, potentially making it difficult for referees to detect and sanction every infringement. ${ }^{13}$ Spitz et al. ${ }^{12}$ found from testing referees in football (soccer) with a visual search paradigm that elite referees spent more time fixating on the most significant aspect of the visual scene (the contact zone), rather than fixating on body parts not involved in the infringement (the non-contact zone), compared to non-elite referees. Further, the ability to cope effectively with the psychological demands of the game is a key determinant of successful rugby union refereeing, ${ }^{22}$ with research aimed at identifying effective coping strategies in other sports. ${ }^{23}$ Anshel et al. ${ }^{23}$ found in Basketball that mental skills training for aspiring referees had strong positive consequences for referees' selfreported quality of management of in-game stressors. World Rugby could implement off-field training for 
referees to increase the likelihood of accurate decisionmaking.

On-field referees are tasked with making complex decisions in limited time and may rely on judgmental heuristics (quick and easy decision laws), to help make their decisions. ${ }^{24}$ Mascarenhas et al. ${ }^{25}$ attempted to quantify the accuracy of referee decisions during match play and found that on-field officials were $50 \%$ accurate in their sanctioning, which was lower than other sports. An explanation to why the accuracy within rugby is so low, may be that the degrees of freedom within a breakdown situation are so great that $50 \%$ accuracy may be appropriate. ${ }^{25}$ Despite this, such studies using video-assessment, ${ }^{25}$ fail to replicate the physical and psychological demands of a match suggesting accuracy of decision-making may be even lower under match conditions. ${ }^{26}$ The abovementioned studies and our current findings suggest that there is a need for future research to investigate why referees are not sanctioning breakdown infringements.

In the current study, referees were not consistent with the application of breakdown laws, with the defending team penalised more often, similar to the findings of Kraak et al. ${ }^{13}$ The referees may have penalised the defending team more frequently to improve the continuity of the game rather than encouraging changing of possession and the need for set pieces. ${ }^{27}$ Kraak et al. ${ }^{13}$ also identify that $5 \%$ of all ruck cleanouts during the 2018 Super Rugby competition were illegal and dangerous. From an injury prevention perspective, Kraak et al. ${ }^{13}$ findings suggest that referees can minimise the risk by focusing on infringements "charged in/shoulder charge", "contact above shoulder" and "neck roll" given the high proportion of these infringements that are deemed dangerous, based on the World Rugby laws of the game. ${ }^{5}$

The television match official (TMO) can contribute to match decision making by utilising multiple camera video review and passing information to the match referee. ${ }^{28}$ Despite this technology, the TMO is limited to intervening on two areas of play: scoring of a try, and possible foul play. It could be argued that to "clean up" the breakdown area, the TMO should be given more power to intervene during open play scenarios. The disadvantage may be that the game could slow significantly, taking away from the fast-paced, dynamic game that fans enjoy.

Given the high number of infringements recorded in this study, the current breakdown laws may not suit the dynamics of modern day rugby union. Perhaps simplifying breakdown laws to cater for the modern game will result in more uniform officiating. One way this could potentially be achieved is to limit the number of players that are allowed to engage in a ruck. However, rule changes can lead to unintended consequences and increased injury rates, ${ }^{29}$ thus further injury and sanctioning monitoring is essential. World Rugby have recently issued a law application guideline for the breakdown, following recommendations by a specialist working group comprising of international coaches, players, and medical experts. ${ }^{30}$ With a focus on player welfare and game attractiveness, the group have opted to impose a strict reinforcement of existing laws rather than changing pre-existing laws. Law 14 and 15 (tackle and ruck) application guidelines are operational for all competitions commencing after 1 July 2020, when stricter sanctioning should be evident with the benefits of rewarding positive play and reducing risk of injury. By sanctioning breakdown infringements appropriately, it may cause a shift in player behaviour and subsequently reduce the number of dangerous illegal breakdowns within the game, however this would need to be assessed.

The current study does not provide a representative picture of breakdown sanctioning within the game as a whole, in lower level competition or in a youth setting. The dynamics of the game and quality of refereeing is likely to be different at different levels of the game. Therefore, surveillance of sanctioning over the course of an entire season, across multiple competitions and levels would be more beneficial in establishing patterns of player adherence and refereeing. Analysis was limited to the television match camera angles. In future projects 'end on' camera views should be requested to mitigate the risk of missing vital breakdown information. Access to audio would have allowed the infringement "use within 5 seconds" to be included in the analysis.

\section{Conclusion}

A high number of infringements occurred at the breakdown in the knockout stages of the 2019 Rugby World Cup. Many infringements went unsanctioned, particularly for dangerous play. The defending team were penalised more than the attacking team, despite making fewer total infringements. The most frequently occurring breakdown infringement was "Head and shoulders below hips" which was not sanctioned once. 'Off feet' and 'offside' were infringements identified yet not appropriately sanctioned. Future work focused on technology, training or rule amendments may be required to improve player adherence and sanctioning of infringements at the breakdown, such that they protect players and are in keeping with the dynamics of the modern game.

\section{Declaration of Conflicting Interests}

The author(s) declared no potential conflicts of interest with respect to the research, authorship, and/or publication of this article. 


\section{Funding}

The author(s) received no financial support for the research, authorship, and/or publication of this article.

\section{ORCID iD}

Gregory J Tierney (D) https://orcid.org/0000-0002-4666-4473

\section{References}

1. Fuller CW, Brooks JH, Cancea RJ, Hall J, et al. Contact events in rugby union and their propensity to cause injury. Br J Sports Med 2007; 41: 862-867.

2. Williams S, Trewartha G, Kemp S, et al. A meta-analysis of injuries in senior men's professional rugby union. Sports Med 2013; 43: 1043-1055.

3. Fuller $\mathrm{CW}$, Ashton $\mathrm{T}$, Brooks $\mathrm{JH}$, et al. Injury risks associated with tackling in rugby union. Br J Sports Med 2010; 44: 159-167.

4. Colomer CME, Pyne DB, Mooney M, et al. Performance analysis in rugby union: a critical systematic review. Sports Med Open 2020; 6: 4.

5. World Rugby. Laws of the game Rugby Union, https:// laws.worldrugby.org/?law $=9$ \&language $=\mathrm{EN} \quad$ (accessed 1 June 2020).

6. McCormick J. Revolutionising rugby - a statistical analysis on how the game has evolved, www.statsperform. com/resource/revolutionising-rugby-a-statistical-analy sis-on-how-the-game-has-evolved/?utm_medium = social \&utm_source $=$ blog\&utm_campaign $=$.revolutionising rugby (accessed 1 June 2020).

7. Mouton J. Understanding the breakdown in rugby, https://ruckscience.com/learn/rugby-breakdown/ (accessed 1 June 2020).

8. Hendricks S, van Niekerk T, Sin DW, et al. Technical determinants of tackle and ruck performance in international rugby union. J Sports Sci 2018; 36: 522-528.

9. Ortega E, Villarejo D and Palao JM. Differences in game statistics between winning and losing rugby teams in the six nations tournament. J Sports Sci Med 2009; 8: 523-527.

10. Kraak WJ and Welman KE. Ruck-Play as performance indicator during the 2010 six nations championship. Int $J$ Sports Sci Coach 2014; 9: 525-537.

11. Mascarenhas DRD, Collins D, Mortimer PW, et al. A naturalistic approach to training accurate and coherent decision making in rugby union referees. Sport Psychol 2005; 19: 131-147.

12. Spitz J, Put K, Wagemans J, et al. Visual search behaviors of association football referees during assessment of foul play situations. Cogn Res Princ Implic 2016; 1: 12.

13. Kraak W, Bam J, Kruger S, et al. Sanctioning of illegal and dangerous ruck cleanouts during the 2018 super rugby competition. Front Psychol 2019; 10: 803-803.

14. Brown JC, Boucher SJ, Lambert M, et al. Nonsanctioning of illegal tackles in South African youth community rugby. J Sci Med Sport 2018; 21: 631-634.
15. Haseler CM, Carmont MR and England $M$. The epidemiology of injuries in English youth community rugby union. $\mathrm{Br} J$ Sports Med 2010; 44: 1093-1099.

16. Tierney GJ and Simms CK. The effect of intended primary contact location on tackler head impact risk. In: IRCOBI conference proceedings, Antwerp, 13-15 September 2017.

17. Tierney GJ, Denvir K, Farrell G, et al. Does ball carrier technique influence tackler head injury assessment risk in elite rugby union? J Sports Sci 2019; 37: 262-267.

18. Tierney GJ and Simms CK. Can tackle height influence head injury assessment risk in elite rugby union? $J \mathrm{Sci}$ Med Sport 2018; 21: 1210-1214.

19. ESPN. World ER. Cup. https://www.espn.co.uk/rugby/, matchstats? gameId $=291186 \&$ league $=289234$ (accessed 1 June 2020).

20. Wilson EB. Probable inference, the law of succession, and statistical inference. J Am Stat Assoc 1927; 22: 209-212.

21. Landis JR and Koch GG. The measurement of observer agreement for categorical data. Biometrics 1977; 33: 159-174.

22. Mascarenhas D, Collins D and Mortimer P. Elite refereeing performance: developing a model for sport science support. Sport Psychol 2004; 19: 364-379.

23. Anshel M, Ekmekci R and Saraswati I. A model linking sources of stress to approach and avoidance coping styles of Turkish basketball referees. J Sports Sci 2013; 32: 116-128.

24. Souchon N, Cabagno G, Traclet A, et al. Referees' decision-making and player gender: the moderating role of the type of situation. J Appl Sport Psychol 2010; 22: 1-16.

25. Mascarenhas DRD, Collins D, Mortimer PW, et al. Training accurate and coherent decision making in rugby union referees. Sport Psychol 2005; 19: 131-147.

26. Emmonds S, O’hara J, Till K, et al. Physiological and movement demands of rugby league referees: influence on penalty accuracy. J Strength Cond Res 2015; 29: 3367-3374.

27. Kraak W, Venter R and Coetzee F. Scoring and general match profile of super rugby between 2008 and 2013. Int J Perf Anal Sport 2016; 16: 786-805.

28. Pearey A. TMO - television match official explained, https://www.rugbyworld.com/tournaments/six-nations2020/tmo-television-match-official-explained-88934 (accessed 1 June 2020).

29. Stokes KA, Locke D, Roberts S, et al. Does reducing the height of the tackle through law change in elite men's rugby union (the championship, England) reduce the incidence of concussion? a controlled study in 126 games. $\mathrm{Br} J$ Sports Med. Epub ahead of print 19 December 2019. DOI: 10.1136/bjsports-2019-101557.

30. R. Referee. New 2020 Tackle law guidelines announced, https://rugbyreferee.net/2020/04/02/new-2020-tacklelaw-guidelines-announced/ (accessed 1 June 2020). 


\section{Appendix I. Breakdown laws from world rugby's 2019 laws of the game. ${ }^{5}$}

\begin{tabular}{|c|c|}
\hline Infringement & Definition \\
\hline A. Head/shoulders below hips & $\begin{array}{l}\text { Players involved in all stages of the ruck must have their heads and shoulders no lower than their } \\
\text { hips. Sanction: Free kick. }\end{array}$ \\
\hline B. Offside & $\begin{array}{l}\text { Each team has an offside line that runs parallel to the goal line through the hindmost point of any } \\
\text { ruck participant. If that point is on or behind the goal line, the offside line for that team is the goal } \\
\text { line. Sanction: Penalty. }\end{array}$ \\
\hline C. Off feet & An arriving player must be on their feet and join from behind their offside line. Sanction: Penalty. \\
\hline D. Bound & $\begin{array}{l}\text { A player must bind onto a team-mate or an opposition player. The bind must precede or be } \\
\text { simultaneous with contact with any other part of the body. Sanction: Penalty. }\end{array}$ \\
\hline E. Hands in ruck & $\begin{array}{l}\text { Once a ruck has formed, no player may handle the ball unless they were able to get their hands on } \\
\text { the ball before the ruck formed and stay on their feet. Sanction: Penalty. }\end{array}$ \\
\hline F. Remaining on feet & Players must endeavour to remain on their feet throughout the ruck. Sanction: Penalty. \\
\hline G. Rolled away & $\begin{array}{l}\text { Players on the ground must attempt to move away from the ball and must not play the ball in the } \\
\text { ruck or as it emerges. Sanction: Penalty. }\end{array}$ \\
\hline H. Use within 5 seconds & $\begin{array}{l}\text { When the ball has been clearly won by a team at the ruck, and is available to be played, the referee } \\
\text { calls "use it", after which the ball must be played away from the ruck within five seconds. } \\
\text { Sanction: Penalty. }\end{array}$ \\
\hline \multirow[t]{10}{*}{ I. Other } & Players must not: \\
\hline & -Pick the ball up with their legs. \\
\hline & -Intentionally collapse a ruck or jump on top of it. \\
\hline & -Intentionally step on another player. \\
\hline & -Fall over the ball as it is coming out of a ruck. \\
\hline & -Kick, or attempt to kick, the ball out of a ruck. \\
\hline & Sanction: Penalty. \\
\hline & -Return the ball into the ruck. \\
\hline & -Take any action to make opponents believe that the ruck has ended when it has not. \\
\hline & Sanction: Free kick. \\
\hline J. (DP) Charged in & $\begin{array}{l}\text { A player must not charge into a ruck or maul. Charging includes any contact made without binding } \\
\text { onto another player in the ruck or maul. Sanction: Penalty. }\end{array}$ \\
\hline K. (DP) Contact above shoulder & $\begin{array}{l}\text { A player must not make contact with an opponent above the line of the shoulders. Sanction: } \\
\text { Penalty. }\end{array}$ \\
\hline L. (DP) Intentional collapse & A player must not intentionally collapse a ruck or a maul. Sanction: Penalty. \\
\hline M. (Tackle) Not releasing & $\begin{array}{l}\text { Tackled players must immediately make the ball available so that play can continue by releasing, } \\
\text { passing or pushing the ball in any direction except forward. Sanction: Penalty. }\end{array}$ \\
\hline
\end{tabular}

